Research Article

\title{
SONOGRAPHIC REFERENCE LUMINAL DIAMETER OF THE ABDOMINAL AORTA AMONG SUBJECTS IN NIGERIA
}

\author{
MICHAEL S. OKPALEKE ${ }^{1}$, VALENTINE C. IKAMAISE ${ }^{2 *}$, KENNETH K. AGWU ${ }^{3}$, ANTHONY C. UGWU1, \\ MICHAEL P. OGOLODOM ${ }^{4}$
}

${ }^{1}$ Department of Radiography, Nnamdi Azikiwe University, Awka, Nigeria. ${ }^{2}$ Department of Radiography and Radiological Science, University of Calabar, Calabar, Nigeria. ${ }^{3}$ Department of Radiography, University of Nigeria, Nsukka, Nigeria. ${ }^{4}$ Department of Rivers State Hospitals Management Board, Port Harcourt, Nigeria. Email: ikamaise@gmail.com or val@unical.edu.ng

Received: 19th October 2020, Revised and Accepted: 20th Novembver 2020

\section{ABSTRACT}

Objective: The objective of the study was to develop a reference luminal diameter (LD) of the abdominal aorta (AA) in Abuja, Nigeria

Methods: The LD of the AA of 422 male and female healthy subjects was measured sonographically using standard protocol. The relationship between age, body mass index (BMI), gender, and the LD of the AA was determined in the subjects. Statistical analysis was performed by the Student's t-test and Pearson's correlation coefficient at $\mathrm{p}<0.05$ level of significance.

Results: The values of the LD of the AA in the healthy subjects were $15.16 \pm 0.55 \mathrm{~mm}$ in males and $15.15 \pm 0.55 \mathrm{~mm}$ in females. The $5^{\text {th }}$ and $95^{\text {th }}$ percentile normal reference limits of the AA were $14.20-16.10 \mathrm{~mm}$, respectively. There were no significant differences in the LD measurements in male and female subjects. Age correlated strongly positively with LD ( $r=0.90)$ of the AA in both genders. BMI showed weak positive correlation with $\mathrm{LD}(\mathrm{r}=0.136)$ of the AA in female healthy subjects only.

Conclusion: The reference LD of the AA in the study population was $15.16 \pm 0.55 \mathrm{~mm}$ in males and $15.15 \pm 0.55 \mathrm{~mm}$ in females. The LD of the AA increased proportionately with age.

Keywords: Aorta, Luminal diameter, Ultrasonography, Reference level, Age.

\section{INTRODUCTION}

The abdominal aorta (AA) is the largest artery in the body with a normal diameter of $20 \mathrm{~mm}$ and supplies major abdominal organs including the liver, spleen, gonads, and diaphragm, with oxygenated blood [1]. Progressing childhood atherosclerosis together with the continuous flow of blood through the AA overtime imposes stress on the walls of the AA and is accompanied by decrease in vessel compliance as well as an increase in aortic wall stiffness [2]. These are caused by changes in the structure of the artery due to increase in the collagen content and formation of plaques, atheroma, intimal atherosclerosis, and thrombus [3], which influence the luminal diameter (LD), leading to abdominal aortic aneurism. The condition becomes worse in the presence of risk factors such as hypertension, diabetes, aging, smoking, and race among others $[1,4,5]$

Abdominal aortic aneurysm is a leading cause of death globally [1] with increasing prevalence in sub-Saharan Africa, especially in Nigeria, where several cases have been diagnosed with associated high mortality [6]. The increase in prevalence and mortality rate of cardiovascular diseases make it a major public health issue in the world [1] causing about 12 million deaths globally and responsible for five out of eight hospital admissions in Nigeria $[7,8]$.

Assessment of changes in vascular structures associated with pathologies is done computed tomography angiography (CTA) magnetic resonance angiography (MRA), and ultrasonography [1,9]. CTA and MRA are expensive, invasive, and not readily available in remote locations in developing countries like Nigeria. Sonographic measurement of the LD of the AA, therefore, provides cheap, sensitive, and readily available method of monitoring these changes and predicting risk of cardiovascular diseases in the locality $[1,7]$.
Despite the reported increased prevalence of cardiovascular diseases and its risks factors as well as the high mortality and morbidity associated with the disease in Nigeria, especially in Abuja metropolis, there are no local baseline reference data to aid accurate diagnosis and identification of people at high risk [7,10-12]. This study is, therefore, designed to establish a local reference data of the AA diameter by ultrasound in Abuja, Nigeria. This study will provide data to serve as a sonographic reference for diagnosis of patients with subclinical cardiovascular diseases and other associated problems as well as providing the needed local content in cardiovascular research.

\section{METHODS}

Four hundred and twenty-two healthy volunteer adult subjects aged between 18 years and 89 years domiciled in Abuja were enlisted into the study between February 2012 and March 2018 using purposive sampling. Ethical approval was obtained from the Research and Ethics Committees of the College of Medicine, University of Nigeria, Enugu campus and the Medicaid Radio-diagnostic Center, Abuja. Informed consent from the volunteer subjects was also obtained. Only consenting healthy volunteer subjects without any clinically and/or laboratory confirmed cardiovascular risk factors were included in the study while subjects with a history of cardiovascular diseases and those with a history of aneurysms were excluded from the study. Anthropometric parameters, namely, height were obtained using a metal tape, weight was obtained using a weighing scale, age was obtained from the date of birth or certificate of birth of the subjects, and body mass index (BMI) was computed as the ratio of weight $(\mathrm{kg})$ to height $\left(\mathrm{m}^{2}\right)$

Afterward, the ultrasonography evaluation of the AA was performed by two experienced sonographers on the enlisted subjects who have fasted for 10-12 h. A Mindray Ultrasound Equipment (4D ultrasound, model - DCN3; year of manufacture - 2013) was used for the measurement. 
Scanning was performed from the level of the diaphragm to the level of bifurcation of the AA at $\mathrm{L}_{4}$ where measurements were made (Fig. 1).

An anteroposterior measurement of the $\mathrm{LD}$ was then made at $90^{\circ}$ to the longitudinal axis of the AA from a longitudinal frozen image on arrested respiration. This allowed correct placement of the calipers at the long axis of the vessel to avoid parallax error. LD was measured by placing calipers at opposite ends of the inner walls of the lumen of the AA. The mean of two LD measurements was recorded (Fig. 2). The following precautions were taken to obtain image of diagnostic quality in obese subjects and subjects with excessive bowel gas. Application of gentle pressure on the abdomen over areas with poor sonographic contrast and some of the subjects were made to turn from the supine position to the lateral decubitus position to dispel bowel gas [13]. The LDs in male and female healthy subjects were analyzed using SPSS package version
23. Descriptive statistics were performed. Student's t-test tool was used to compare variable and percentile values were used to obtain lower and upper limits of LD of the AA. The Pearson's correlation coefficient was used to obtain the association between age, BMI, gender, and the LD of the AA.

\section{RESULTS}

The results showed that values of the LD of the AA in the healthy subjects were $15.16 \pm 0.55 \mathrm{~mm}$ in males and $15.15 \pm 0.55 \mathrm{~mm}$ in females, respectively (Table 1 ). The $5^{\text {th }}$ and $95^{\text {th }}$ percentile normal reference limits of the AA obtained were 14.20-16.10 mm, respectively (Table 2). There were no significant differences in the LD measurements in male and female subjects (Table 3 ). Age correlated significantly positively with LD $(r=0.90)$ of the AA in both genders. BMI showed weak

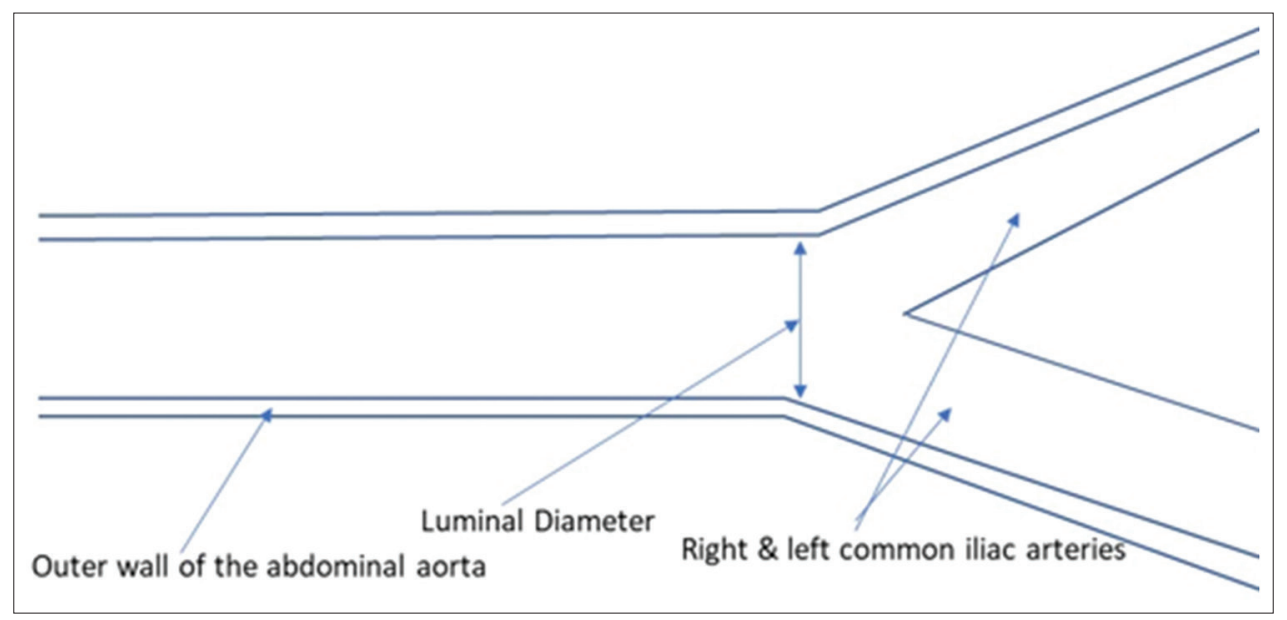

Fig. 1: Schematic diagram for the measurement of the luminal diameter of the abdominal aorta

Table 1: Variations in LD of male and female subjects

\begin{tabular}{|c|c|c|c|c|c|}
\hline \multirow{2}{*}{$\begin{array}{l}\text { Age range } \\
\text { (years) }\end{array}$} & \multicolumn{2}{|c|}{ LD in male subjects (mm) } & \multicolumn{2}{|c|}{ LD in female subjects (mm) } & \multirow[t]{2}{*}{ T-test } \\
\hline & Range & Mean \pm SD & Range & Mean \pm SD & \\
\hline $18-32$ & $14.01-14.40$ & $14.97 \pm 0.27$ & $14.00-14.40$ & $14.28 \pm 0.14$ & 0.869 \\
\hline $33-47$ & $14.20-15.20$ & $14.97 \pm 0.27$ & $14.20-15.20$ & $14.96 \pm 0.28$ & 0.908 \\
\hline $48-62$ & $15.21-15.40$ & $15.31 \pm 0.88$ & $15.20-15.40$ & $15.31 \pm 0.085$ & 0.726 \\
\hline $63-77$ & $15.40-16.40$ & $15.50 \pm 0.29$ & $15.40-16.40$ & $15.52 \pm 0.33$ & 0.618 \\
\hline $78-92$ & $15.52-16.50$ & $15.89 \pm 0.40$ & $15.50-16.50$ & $15.84 \pm 0.38$ & 0.874 \\
\hline Total & & $15.16 \pm 0.55$ & & $15.15 \pm 0.55$ & 0.931 \\
\hline
\end{tabular}

${ }^{*}$ Significant mean difference at $\mathrm{p}<0.05$. LD: Luminal diameter

Table 2: The percentile values of abdominal aorta diameter in healthy subjects

\begin{tabular}{|c|c|c|c|c|c|c|c|c|}
\hline \multicolumn{2}{|l|}{ Parameter } & \multicolumn{7}{|c|}{ Percentile range in healthy subjects } \\
\hline & Mean (SD) & 5 & 10 & 25 & 50 & 75 & 90 & 95 \\
\hline Luminal diameter $(\mathrm{mm})$ & $15.16 \pm 0.55$ & 14.200 & 14.300 & 14.875 & 14.200 & 14.400 & 15.500 & 16.100 \\
\hline
\end{tabular}

Table 3: Age, BMI, and gender distribution of the volunteer healthy subjects

\begin{tabular}{|c|c|c|c|c|c|c|c|c|}
\hline \multirow[t]{3}{*}{ Age range } & \multicolumn{4}{|c|}{ Male volunteer subjects } & \multicolumn{4}{|c|}{ Female volunteer subjects } \\
\hline & \multirow[t]{2}{*}{$* \mathbf{n}$} & \multirow{2}{*}{$\begin{array}{l}\text { Age (years) } \\
\text { Mean }\end{array}$} & \multicolumn{2}{|l|}{ BMI } & \multirow[t]{2}{*}{$* \mathbf{n}$} & \multirow{2}{*}{$\frac{\text { Age (years) }}{\text { Mean }}$} & \multicolumn{2}{|l|}{ BMI } \\
\hline & & & Range & Mean & & & Range & Mean \\
\hline $18-32$ & (37) & $25.54 \pm 4.63$ & $16.58-32.90$ & $26.07 \pm 3.37$ & (37) & $25.54 \pm 4.63$ & $20.20-36.90$ & $25.73 \pm 4.06$ \\
\hline $33-47$ & (52) & $40.19 \pm 4.54$ & $14.80-33.31$ & $24.01 \pm 4.50$ & (53) & $40.22 \pm 4.50$ & $14.80-32.83$ & $24.79 \pm 4.45$ \\
\hline $48-62$ & (58) & $34.22 \pm 3.79$ & $19.85-42.40$ & $27.31 \pm 4.75$ & (57) & $54.31 \pm 3.77$ & $17.90-42.40$ & $27.21 \pm 5.05$ \\
\hline $63-76$ & (33) & $68.30 \pm 4.40$ & $23.23-45.20$ & $29.43 \pm 5.75$ & (34) & $69.21 \pm 4.33$ & $20.70-45.20$ & $28.05 \pm 5.27$ \\
\hline $78-90$ & (31) & $82.65 \pm 3.19$ & $23.20-38.20$ & $27.20 \pm 3.23$ & (30) & $82.63 \pm 3.25$ & $20.90-30.10$ & $25.80 \pm 2.28$ \\
\hline Total & $(50)$ & $52.27 \pm 19.02$ & $14.80-45.20$ & $26.59 \pm 4.79$ & $(50)$ & $52.15 \pm 18.94$ & $14.80-45.20$ & $26.59 \pm 4.80$ \\
\hline
\end{tabular}

*n: number, BMI: Body mass index 
significant correlation with LD $(r=0.136)$ of the AA in female healthy subjects under study (Table 4).

\section{DISCUSSION}

In this study, 422 subjects were recruited which consist of 211 male healthy subjects representing $50 \%$ of the studied population and 211 female subjects also representing another 50\% of the studied population, thereby giving a male-to-female ratio of $1: 1$

The normal mean value of the LD in the present study is $15.16 \pm 0.55 \mathrm{~mm}$ in males and $15.15 \pm 0.55 \mathrm{~mm}$ in females (Table 1 ). The upper and lower normal reference limits were $14.20-16.10 \mathrm{~mm}$ representing the $5^{\text {th }}$ and $95^{\text {th }}$ percentiles, respectively (Table 2 ). These are similar to the aortic diameter measurements reported in another Nigerian population [8] but higher than the values reported in a related study in a Sudanese population [14]. Usman et al. [7] reported a mean transverse infrarenal outer to outer AA diameter of $16.3 \pm 2.3 \mathrm{~mm}$ although the AA was measured using the outer to outer method instead of the inner to inner method used in the present study. The reference values in the present study were less than that reported in healthy AfricanAmerican population and other Caucasians in the multiethnic study of atherosclerosis (MESA) [15] but higher than the measurements obtained in an Indian population [16] using computed tomography. The MESA study reported that the abdominal aortic diameter of AfricanAmericans was smaller than those of other Caucasians. The fact that ultrasound measurements consistently underestimates aortic size up to $5 \mathrm{~mm}$ compared to computed tomography measurements [17] implies that ultrasound equivalent of the computed tomography measurements will be much higher, especially in Caucasians. Recent studies, however, suggest that there were no significant differences in abdominal aortic diameter measurements between computed tomography and ultrasonography [18]. The differences between the present study and the previous studies were attributed to differences in levels of measurement, methodology, and racial factors $[15,19]$. These regional

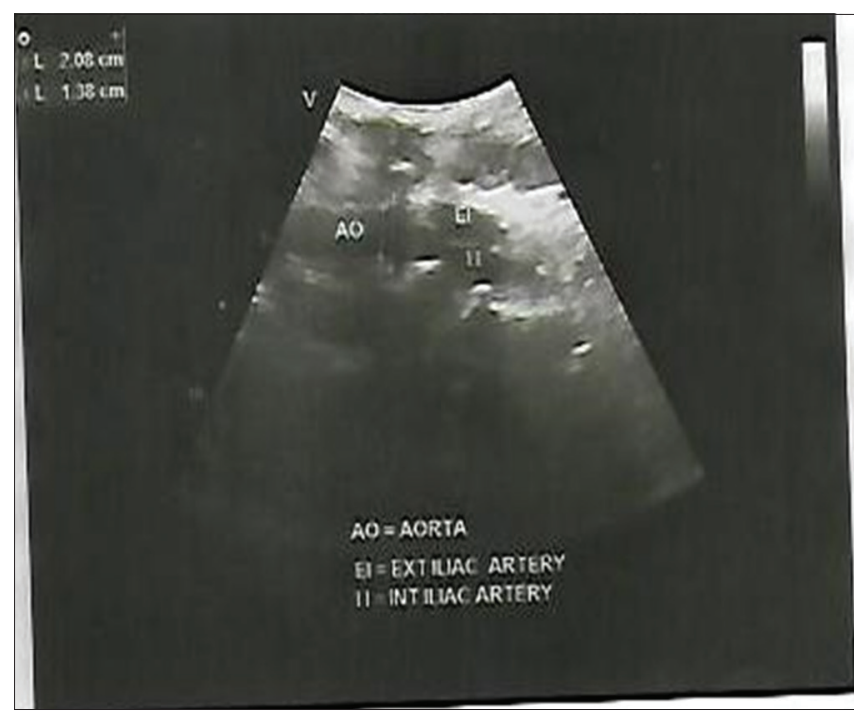

Fig. 2: Sonograph showing the longitudinal measurements of luminal diameter of the abdominal aorta in healthy subjects

Table 4: Relationship between age, body mass index, and luminal diameter (LD)

\begin{tabular}{lll}
\hline Parameters & LD & \\
\cline { 2 - 3 } & Male & Female \\
\hline Age (r) & 0.902 & 0.899 \\
Body mass index (r) & 0.214 & $0.136^{*}$ \\
\hline
\end{tabular}

and racial differences, therefore, suggest that genetic and racial factors play important roles in influencing AA diameter. Furthermore, another factor responsible for the widening of the AA in the population was age. In the present study, we observed that the AA increased in thickness with age and was more pronounced in subjects above 48 years with maximum LD dilatation seen in subjects above 90 years of age (Table 3). The LD of the AA also widened with increasing age in both male and female healthy subjects. This was depicted by the strong positive correlation and association between age and LD measurements (Table 4). These findings have been collaborated by related studies $[14,16]$. Therefore, increasing age, especially old age, seems to play a role in AA dilatations and stiffness. Healthy male subjects have statistically non-significant wider LD than healthy female subjects (Table 1). Other related studies have also found significant differences in the AA diameters of male and female subjects contrary to the findings of the present study $[13,14]$. The differences between the earlier studies and the present study are attributed to differences in methodology. The fact that the widening of LD in both genders occurred simultaneously implies that the development of aortic atherosclerotic lesions which is a risk factor of cardiovascular disease may predispose both male and female adult's subjects in the locality to early onset of cardiovascular diseases and aneurismal dilatations.

BMI showed weak association with LD of the AA in both male and female healthy subjects (Table 4,) and this has been collaborated by related studies [7]. There were significant mean differences in the BMI and LD in female subjects but not in male subjects (Table 4). This implies that BMI is an important factor to consider in the clinical evaluation of luminal dilatations of the AA in female subjects in the present study. This agrees with the findings of another related study which documented that the indices of body size such as height, weight, and BMI influence AA diameter more in female subjects than in male subjects [20]. Another study opined that BMI is significantly associated with increases in AA diameter in both male and female subjects at the bifurcation level of the AA by ultrasound unlike in the present study where we observed weak positive correlation between LD of the AA and BMI with significant correlations seen only in female subjects.

The difference between the result of the present study and earlier studies may be attributed to race and environmental factors. Age and BMI significantly and collectively predicted widening of the LD in healthy volunteer subjects by $81 \%\left(R^{2}=0.811\right)$ by multiple regression analysis. However, only age remained the single independent predictor of AA luminal dilatations $(\beta=0.594)$ in stepwise regression analysis.

\section{CONCLUSION}

The reference LDs of the AA in the locality were $15.16 \pm 0.55 \mathrm{~mm}$ in males and $15.15 \pm 0.55 \mathrm{~mm}$ in females. Age is the only significant independent predictor of dilatations of the LD of the AA. The LD for males and females is presented as the reference values for sonographic scans in the population of study.

\section{REFERENCES}

1. Hussain AY, Dakpa T, Fardous M, Melo F, Matinez F, Brzostowski B. Role of ultrasound in the diagnosis of abdominal aortic aneurysm. Ecronicon Cardiol 2018;5:955-68.

2. Kozaburo H, Tomoyuki Y, Akira T, Kohji S. Clinical assessment of arterial stiffness with cardio-ankle vascular index: Theory and applications. J Hyperten 2015;33:1742-57.

3. Raimund E, Holger EB. Aortic dimensions and the risk of dissection. $\mathrm{Br}$ Med J 2006;92:137-42.

4. Escudero CA, Herlitz K, Troncoso F, Guevara K, Acurio J, Aguayo C, et al. Pro-angiogec role of insulin: From physiolonigy to pathology. Front Physiol 2017;8:204

5. Moxon JV, Par A, Emeto TI, Walker P, Norman PE, Golledge J. Diagnosis and monitoring of abdominal aortic aneurysm: Current status and future prospects. Curr Problems Cardiol 2011;35:512-8.

6. Ogunleye EO, Adekola OO, Dada OI. Aortic aneurysm: A life-threatening condition in a low-resource nation. J Clin Sci 2019;2019:252274. 
7. Usman BO, Lawal S, Ibinaiye PO, Chom ND, Umar A. Determination of normal supra and infra renal aortic diameter on ultrasound in Zaria, Nigeria. West Afr J Ultrasound 2014;15:1-24.

8. Dokunmu T, Yakubu OF, Adebayo AF, Oleshinde GI, Chinedu SW Cardiovascular risk factor in suburban community in Nigeria. Int $\mathrm{J}$ Hyperten 2018;2018:527-33.

9. Guedes-Martins L, Ana C, Joaquim S, Ana R, Anas SC, Fillipe M, et al. Foetal aortic flow velocity waveforms in healthy and hypertensive pregnant women. J Cardiovasc Ultrasound 2014;12:1476-7120.

10. Eze JC, Ezemba N, Adamu YA. Study of extra-cranial aneurysms at UNTH in Enugu Nigeria. Niger J Clin Pract 2010;13:272-5.

11. Chinakwana GU, Odike MA, Nwafor AM. Problems and prospects of managing thoracic aortic aneurysm at Nnamdi Azikiwe university teaching hospital, Nnewi Nigeria. World J Surg 2014;28:288-90.

12. Ogbera OA, Chukwuma EB. Diabetes mellitus in Nigeria: The past, present and future. World J Diabetes 2014;5:905-11.

13. Reardon RF, Clinton ME, Madore F, Cook TP. Abdominal aortic aneurysm. In: Ma O, Mater JR, Readon RF, Joing SA. Emergency Ultrasound. $3^{\text {rd }}$ ed. New York; McGraw-Hill; 2014.

14. Moawia G. Normal abdominal aorta diameter on abdominal sonography in healthy asymptomatic adult: The impact of age and gender. J Radiation Res Appl Sci 2019;12:186-91.
15. Laughlin GA, Allison MA, Jensky NE, Aboyans V, Wong ND, Detrano R. Abdominal aortic diameter and vascular atherosclerosis: The multi-ethnic study of atherosclerosis. Eur J Vasc Endovasc Surg 2011;41:481-7.

16. Jasper A, Harshe G, Keshava SN, Kulkarni G, Stephen E, Agarwal S. Evaluation of normal abdominal aortic diameters in the Indian population using computed tomography. J Postgrad Med 2014;60:57-60.

17. Chiu K, Lung L, Tripathi V, Ahmed M, Shrivastira V. Ultrasound measurement for abdominal aortic aneurysm screening; a direct comparison of three leading leading methods. Eur J Vasc Endovasc Surg 2014; 47:367-73

18. Liisberg $M$, Diederichsen AC, Lindholt JS Abdominal ultrasound scanning versus non-contrast computed tomography screening method for abdominal aortic aneurysm-a validation study from the randomized DANCAVAS study. BMC Med Imaging 2017;17:8.

19. Adam DT, David LT, Levente LZ, Solt G, Kinga K, Viktor B. Genetic and environmental effects on the abdominal aortic diameter development. Arq Bras Cardiol 2016;106:13-7.

20. Lo RC, Lu B, Fokkema M, Conrad M, Patel V, Fillinger M, et al. Relative importance of aneurysm diameter and body size for predicting abdominal aortic aneurysm rupture in men and women. J Vasc Surg 2014;59:1209-6. 